\title{
A Study on Ductility of Prestressed Concrete Pier Based on Response Surface Methodology
}

\author{
Huili Wang \\ Institute of Bridge Engineering \\ Dalian University of Technology \\ Dalian, China \\ wanghuili@dlut.edu.cn
}

\author{
Yan Zhang \\ Institute of Bridge Engineering \\ Dalian University of Technology \\ Dalian, China \\ 18342209879@163.com
}

\author{
Sifeng Qin \\ Numerical Test Research Center \\ for Materials Fracture Mechanics \\ Dalian University, Dalian, China \\ qsifeng@163.com
}

\begin{abstract}
The ductility of prestressed concrete pier is studied based on response surface methodology. Referring to the pervious prestressed concrete pier, based on Box-Behnken design, the ductility of $\mathbf{2 5}$ prestressed concrete piers is calculated by numerical method. The relationship between longitudinal reinforcement ratio, shear reinforcement ratio, prestressed tendon quantity, concrete compressive strength and ductility factor is gotten. The influence of the longitudinal reinforcement ratio, the shear reinforcement ratio, the prestressed tendon quantity and concrete compressive strength to curvature ductility is discussed. Then the ductility regression equation is deduced. The result showed that the influence of the prestressed tendon quantity to the ductility of prestressed concrete pier is significant. With the increasing of the prestressed tendon quantity, the curvature ductility curved reduces. With the increasing of shear reinforcement ratio and compressive strength of concrete, the curvature ductility increases linearly. And the influence of the longitudinal reinforcement ratio to ductility of the prestressed concrete pier is insignificant.
\end{abstract}

Keywords-response surface methodology; experiment design; prestressed concrete; pier; ductility

\section{INTRODUCTION}

The application of PreStressed Concrete (PRC) pier has increased because of its efficiency and high quality. Precast segmental construction methods can cut construction costs by reducing construction time while maintaining quality. In addition, because of the self-centering capability of prestressed tendon, PRC pier could meet the performance requirement during the normal use stage as well as improve the seismic performance of a whole bridge [1]. Many researchers have investigated the seismic performance of PRC pier. Hewes and Priestley investigated the performance of unbonded posttensioned precast concrete segmental bridge columns under lateral earthquake loading [2]. In [3], authors studied the seismic performance, identify the key design variables, and evaluate the effect of different ground motions and different column configurations for a self-centering reinforced concrete column with unbonded prestressing strand placed at the center of the cross section. In [4], authors investigated the seismic

This work was supported by Foundation of China Scholarship Council (201506060044, 201508210247); Foundation of Liaoning Provincial Department of Education Funded Projects (L2014027) performance of unbonded prestressed hollow concrete columns constructed with precast segments. In [5], authors tested several different pier bents in a four-span bridge earthquake simulation study. In [6], authors investigated the response of segment joints using detailed non-linear time-history analyses. A suite of ten near field earthquake records was used to determine the median joint response as well as to quantify the effect of vertical motion on the joint response. The authors showed that a prestressed bar could increase pier self reset capability and decrease the residual displacement of the bridge pier under earthquake. The mechanical properties of PRC pier are relation to some parameters, such as the longitudinal reinforcement ratio, the shear reinforcement ratio, the prestressed tendon quantity and compressive strength of concrete. The parameters analysis can be conducted with the statistical analysis methodology.

Response Surface Methodology (RSM) represents a collection of statistical and mathematical techniques and it is often used for development, improvement and optimization of various processes, where certain response is influenced by several variables. In [7], authors used RSM to investigate the performance of corroding under-reinforced beams. In [8], authors adopted he RSM to create response surface functions of the specific energy for thin-walled columns. In [9], authors used RSM to estimate the representative fragility curves for horizontally curved steel, I-girder bridges in conjunction with Monte Carlo simulation. Experimental design is widely used for controlling the effects of parameters in many processes. Its usage decreases the number of experiments, using time and material resources. Central Composite Design (CCD) and Box Behnken Design (BBD) are usually adopted in RSM. CCDs are a factorial or fractional factorial design with center points, augmented with a group of axial points [10]. BBD is a type of response surface design that does not contain an embedded factorial or fractional factorial design [11]. In [12], BBD was emp[loyed to optimize the indomethacin-loaded chitosan nanoparticle size. In [13], BBD was used to optimize the nanoscale retrograded starch formation. In [14], BBD was applied for fabrication of titanium alloy and 304 stainless steel joints.

The present paper investigates the ductility of prestressed concrete pier through response surface methodology. The 
influence of the longitudinal reinforcement ratio, the shear reinforcement ratio, the prestressed tendon quantity and concrete strength grade to curvature ductility is discussed.

\section{RESPONSE SURFACE METHODOLOGY}

Response surface methodology (RSM) is a collection of statistical and mathematical methods that are useful for modeling and analysis engineering problems. Response surface methodology was developed by Box and collaborators in the 1950 s [15]. The design procedure of response surface methodology is as follows $[11,16]$ :

- Designing of a series of experiments for adequate and reliable measurement of the response of interest.

- Choosing of the experimental design and carrying out the experiments according to the selected experimental matrix.

- Getting the experimental results by serial experiments.

- Mathematic-statistical treatment of the obtained experimental data through the fit of a polynomial function.

\section{A. Mathematical Model}

The simplest model which can be used in RSM is based on a linear function [17].

$$
\mathrm{y}=\beta_{0}+\sum_{\mathrm{i}=1}^{\mathrm{k}} \beta_{\mathrm{i}} \mathrm{x}_{\mathrm{i}}+\varepsilon
$$

Where $\beta_{0}, \beta_{1}$ represents the coefficients of the linear parameters, $x_{i}$ represents the variables, $\mathrm{k}$ is the number of variables, and $\varepsilon$ is the residual associated with the experiments. To evaluate curvature, a second-order model must be used. In order to determine a critical point (maximum, minimum, or saddle), it is necessary for the polynomial function to contain quadratic terms according to the equation presented below ${ }^{[17]}$ :

$$
\mathrm{y}=\beta_{0}+\sum_{\mathrm{i}=1}^{\mathrm{k}} \beta_{\mathrm{i}} \mathrm{x}_{\mathrm{i}}+\sum_{\mathrm{i}=1}^{\mathrm{k}} \beta_{\mathrm{ii}} \mathrm{x}_{\mathrm{i}}^{2}+\sum_{1 \leq \mathrm{i} \leq \mathrm{j}}^{\mathrm{k}} \beta_{\mathrm{ij}} \mathrm{x}_{\mathrm{i}} \mathrm{x}_{\mathrm{j}}+\varepsilon
$$

where $b_{i i}, \beta_{i j}$ represents the coefficients of the quadratic parameter.

\section{B. Experimental design}

The parameters analysis could be conducted with statistical analysis methodology. In this study, BBD was chosen. For $\mathrm{BBD}$, the design points fall at combinations of the high and low factor levels and their midpoints. Box and Behnken suggested how to select points from the three-level factorial arrangement, which allows the efficient estimation of the firstand second-order coefficients of the mathematical model. BBDs have treatment combinations that are at the midpoints of the edges of the experimental space and require at least three continuous factors [18], shown in Figure 1. Because BBDs often have fewer design points, they can be less expensive to do than central composite designs with the same number of factors. Table I contains the coded values of the factor levels for $\mathrm{BBD}$ on three factors. (a)

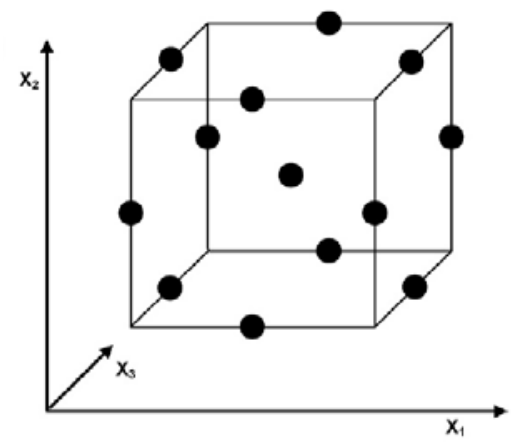

(b)

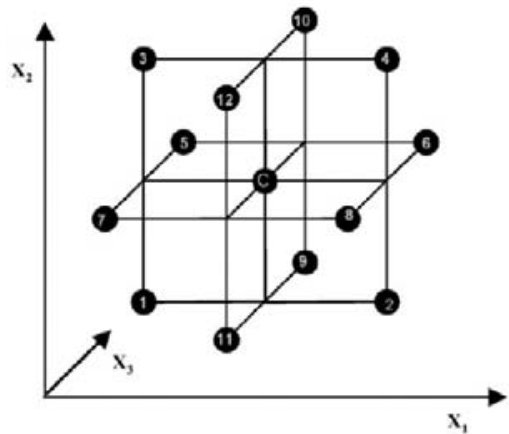

Fig. 1. BBD cube for 3 factors: (a) cube for BBD and three interlocking 3 factorial design, (b) points for BBD and three interlocking 3 factorial design:

TABLE I. BBD TABLE FOR 3 FACTORS

\begin{tabular}{|c|c|c|c|}
\hline Number & $\mathrm{x}_{1}$ & $\mathrm{X}_{2}$ & $\mathrm{x}_{3}$ \\
\hline 1 & -1 & -1 & 0 \\
\hline 2 & 1 & -1 & 0 \\
\hline 3 & -1 & 1 & 0 \\
\hline 4 & 1 & 1 & 0 \\
\hline 5 & -1 & 0 & -1 \\
\hline 6 & 1 & 0 & -1 \\
\hline 7 & -1 & 0 & 1 \\
\hline 8 & 1 & 0 & 1 \\
\hline 9 & 0 & -1 & -1 \\
\hline 10 & 0 & 1 & -1 \\
\hline 11 & 0 & -1 & 1 \\
\hline 12 & 0 & 1 & 1 \\
\hline $\mathrm{C}$ & 0 & 0 & 0 \\
\hline
\end{tabular}

\section{THE DUCTILITY CAPACITY OF PRESTRESSED CONCRETE} PIER

\section{A. Constitutive Relations}

\section{1) Concrete}

The concrete damage plasticity (CDP) model was adopted [19]. A general constitutive relationship for CDP model is shown in Figure 2, where $\varepsilon_{\text {un }}^{\mathrm{m}}$ and $\sigma_{\text {un }}^{\mathrm{m}}$ presents strain and stress of m-th tipping point, $\varepsilon_{\mathrm{pl}}^{\mathrm{m}}$ is the concrete compressive plastic strain on $\mathrm{m}$-th loading, $d_{c}$ is compressive damage factor, and $\underline{d}_{t}$ is tensile damage factor. Compression section was defined as [20]: 


$$
\sigma=\left\{\begin{array}{l}
\mathrm{f}_{\mathrm{c}}\left[2 \frac{\varepsilon}{\varepsilon_{0}}-\left(\frac{\varepsilon}{\varepsilon_{0}}\right)^{2}\right] \quad \quad \varepsilon \leq \varepsilon_{0} \\
\mathrm{f}_{\mathrm{c}}\left[1-0.15 \frac{\varepsilon-\varepsilon_{0}}{\varepsilon_{\mathrm{u}}-\varepsilon_{0}}\right] \quad \varepsilon_{0} \leq \varepsilon \leq \varepsilon_{\mathrm{u}}
\end{array}\right.
$$

where $f_{c}=$ uniaxial compressive strength of concrete, $\varepsilon_{0}=$ yield strain, $\varepsilon_{\mathrm{u}}=$ ultimate compressive strain. Tension section was defined as

$$
\sigma=\mathrm{f}_{\mathrm{t}} \frac{\frac{\varepsilon}{\varepsilon_{\mathrm{t}}}}{\mathrm{a}_{\mathrm{t}}\left(\frac{\varepsilon}{\varepsilon_{\mathrm{t}}}-1\right)^{1.7}+\frac{\varepsilon}{\varepsilon_{\mathrm{t}}}} \quad \varepsilon \geq \varepsilon_{\mathrm{t}}
$$

where $a_{t}=0.312 f_{t}^{2}, f_{t}=$ uniaxial ultimate tensile stress of concrete, $\varepsilon_{\mathrm{t}}=$ peak tensile strain of concrete [21].

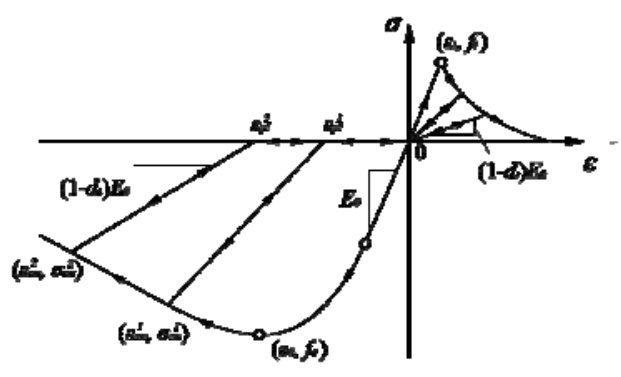

Fig. 2. Constitutive relationship for CDP model

\section{2) Reinforcement}

Bilinear kinematic (BKIN) hardening of material was used to define the behavior of the steel bar. Material properties for the bar were as follows [20]: elastic modulus $\mathrm{E}_{\mathrm{s}}=200 \mathrm{GPa}$; yield stress $\mathrm{f}_{\mathrm{y}}=335 \mathrm{MPa}$; yield strain $\varepsilon_{\mathrm{y}}=0.00168$ and $0.1 \mathrm{E}_{\mathrm{s}}$ as the slope of the hardening phase. BKIN model for the steel bar behavior for unloading and reloading branches is shown in Figure 3.

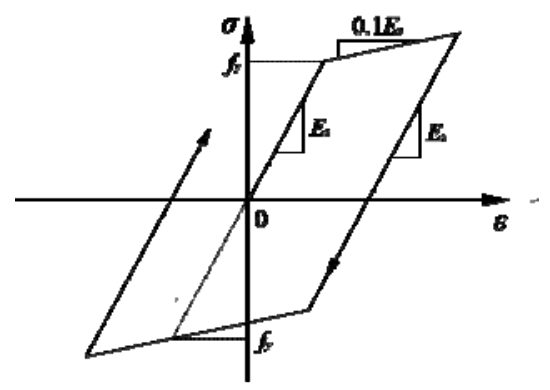

Fig. 3. Constitutive relationship for reinforcement

\section{3) PT strands}

In this study, the mechanical model of the PT strands was also defined as a BKIN model [20], where elastic ratio of prestressing tendons $E_{s}=195 \mathrm{GPa}$, yield stress $\mathrm{f}_{\mathrm{y}}=1860 \mathrm{MPa}$; yield strain $\varepsilon_{\mathrm{y}}=0.00954$ and $0.1 \mathrm{E}_{\mathrm{s}}$ as the slope of the hardening phase. Effective tensile stress $\sigma_{\text {con }}=800 \mathrm{MPa}$ which was equivalent to $43 \%$ of the ultimate tensile strength, and axial compression ratio $\mathrm{u}=22.7 \%$.

\section{B. Definition of ductility}

Because of inelastic deformation capacity of reinforced concrete ductility members depends on cross section of plastic rotation capacity in plastic hinge zone, through responding to the ductility capacity of prestressed concrete could compute cross section curvature ductility coefficient [22]. A measure of the ductility of structures with regard to seismic loading is the displacement ductility factor defined as $\Delta \mathrm{u} / \Delta \mathrm{y}$, where $\Delta \mathrm{u}$ is the lateral deflection at the end of the post-elastic range and $\Delta y$ is the lateral deflection at first yield. A rotational ductility factor for members has been calculated by some dynamic analyses as [23]

$$
\mu_{\varphi}=\frac{\varphi_{\mathrm{u}}}{\varphi_{\mathrm{y}}}
$$

where $\varphi_{\mathrm{u}}=$ maximum curvature at the section and $\varphi_{\mathrm{y}}=$ curvature of the section at first yield, as shown in Figure 4 .

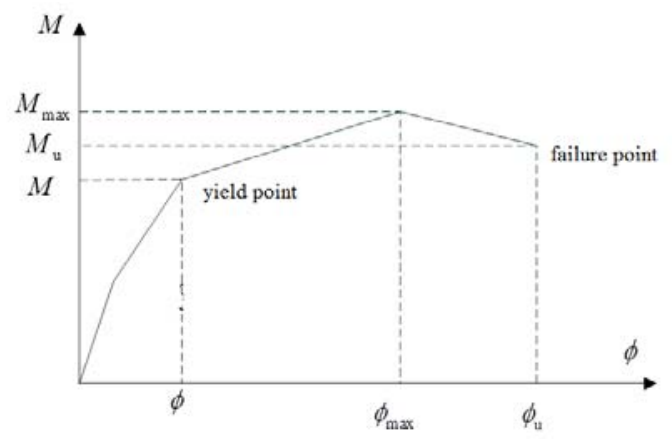

Fig. 4. Moment-Curvature relationship

The curvature ductility coefficient of a structure is usually much bigger than its displacement ductility factor in the plastic hinge zone. The reason is that rotation of plastic hinge becomes the main deformation while yield occurring [24]. In this paper, members will yield if the outermost longitudinal tensile plain reinforcement of reinforced concrete members reach to the initial yield curvature. The ductility of PRC pier are relation to the longitudinal reinforcement ratio, the shear reinforcement ratio, the prestressed tendon quantity and compressive strength of concrete. Referring to pervious prestressed concrete pier, based on $\mathrm{BBD}$, it is operable to analyze ductility of PRC pier with FEM.

\section{CASE STUDY}

One bridge pier circular cross section is 2 meters in diameter, just as shown in Figure 5. The ratio of longitudinal reinforcement $\mathrm{x}_{1}$ would take the values of $0.80 \%, 1.00 \%$ and $1.20 \%$. The shear reinforcement ratio $\mathrm{x}_{2}$ would take the values of $0.03 \%, 0.035 \%$ and $0.04 \%$. The prestressed tendon $\mathrm{x}_{3}$ would 
take the values of $\Phi 15.27-10, \Phi 15.27-15$ and $\Phi 15.27-20$. The concrete strength grade $\mathrm{x}_{4}$ would take the values of 30,40 and 50. There are four factors with three level. Base on BBD, the experiment design and ductility coefficient results y are shown in Table II.

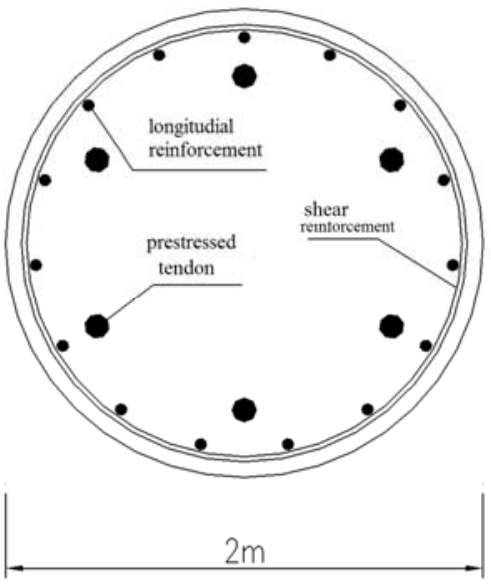

Fig. 5. Geometrical characteristic of the tested pier section

TABLE II. THE EXPERIMENT DESIGN AND RESULTS

\begin{tabular}{|r|c|c|c|c|c|}
\hline No. & $\mathrm{X}_{1}(\%)$ & $\mathrm{X}_{2}(\%)$ & $\mathrm{X}_{3}$ & $\mathrm{X}_{4}(\mathrm{MPa})$ & $\mathrm{y}$ \\
\hline 1 & 1.0 & 0.040 & 20 & 40 & 4.204 \\
\hline 2 & 1.0 & 0.040 & 15 & 30 & 4.378 \\
\hline 3 & 0.8 & 0.035 & 15 & 50 & 6.998 \\
\hline 4 & 0.8 & 0.035 & 20 & 40 & 4.109 \\
\hline 5 & 1.0 & 0.030 & 15 & 30 & 3.822 \\
\hline 6 & 1.0 & 0.035 & 10 & 50 & 11.67 \\
\hline 7 & 1.0 & 0.035 & 10 & 30 & 6.979 \\
\hline 8 & 1.0 & 0.040 & 15 & 50 & 7.270 \\
\hline 9 & 1.0 & 0.035 & 20 & 50 & 4.778 \\
\hline 10 & 1.2 & 0.030 & 15 & 40 & 5.260 \\
\hline 11 & 1.0 & 0.030 & 10 & 40 & 8.720 \\
\hline 12 & 1.0 & 0.040 & 10 & 40 & 9.304 \\
\hline 13 & 1.2 & 0.035 & 10 & 40 & 8.995 \\
\hline 14 & 1.0 & 0.035 & 15 & 40 & 5.476 \\
\hline 15 & 0.8 & 0.035 & 10 & 40 & 8.940 \\
\hline 16 & 0.8 & 0.030 & 15 & 40 & 5.681 \\
\hline 17 & 1.0 & 0.030 & 15 & 50 & 6.687 \\
\hline 18 & 1.0 & 0.030 & 20 & 40 & 3.971 \\
\hline 19 & 0.8 & 0.040 & 15 & 40 & 6.098 \\
\hline 20 & 1.0 & 0.035 & 20 & 30 & 2.777 \\
\hline 21 & 1.2 & 0.035 & 15 & 50 & 7.042 \\
\hline 22 & 0.8 & 0.035 & 15 & 30 & 4.278 \\
\hline 23 & 1.2 & 0.040 & 15 & 40 & 5.648 \\
\hline 24 & 1.2 & 0.035 & 20 & 40 & 4.146 \\
\hline 25 & 1.2 & 0.035 & 15 & 30 & 3.989 \\
\hline
\end{tabular}

With statistical analysis and ignore insignificant quadratic term, the ductility regression equation is deduced.

$$
\begin{aligned}
& y=9.48720-4.05461 x_{1}-55.14804 x_{2} \\
& -1.04795 x_{3}+0.35360 x_{4} \\
& -3.51000 x_{2} x_{3}-0.013450 x_{3} x_{4}+1.81397 x_{1}{ }^{2} \\
& +2197.35294 x_{2}{ }^{2}+0.039947 x_{3}{ }^{2}
\end{aligned}
$$

Based on (6), the influence of each factor to curvature ductility is discussed. The results are shown in Figures 6-8.

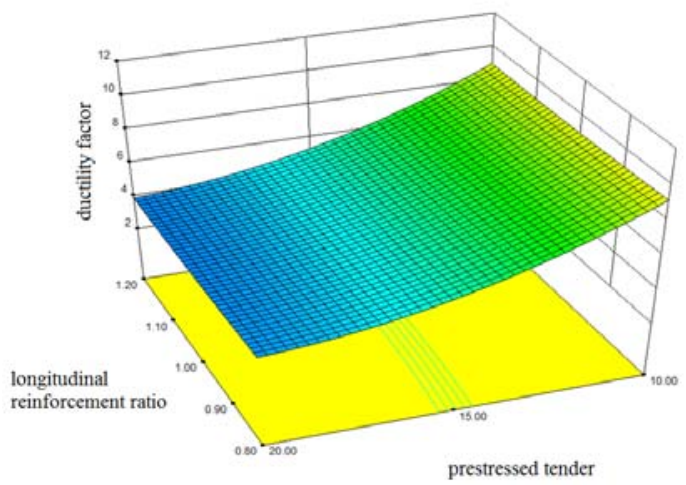

Fig. 6. Relationship between longitudinal reinforcement ratio, prestressed tendon and ductility factor

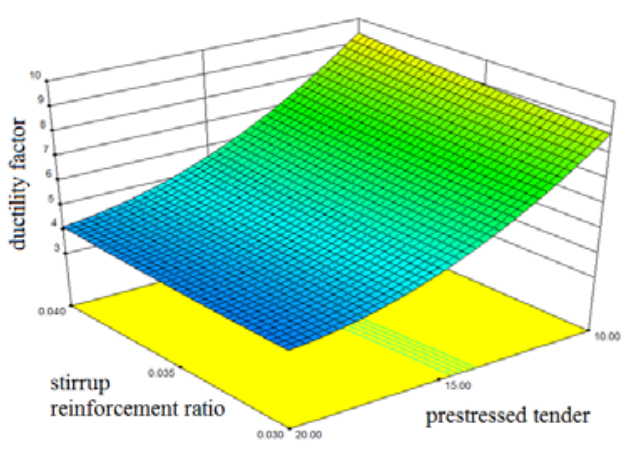

Fig. 7. Relationship between shear reinforcement ratio, prestressed tendon and ductility factor

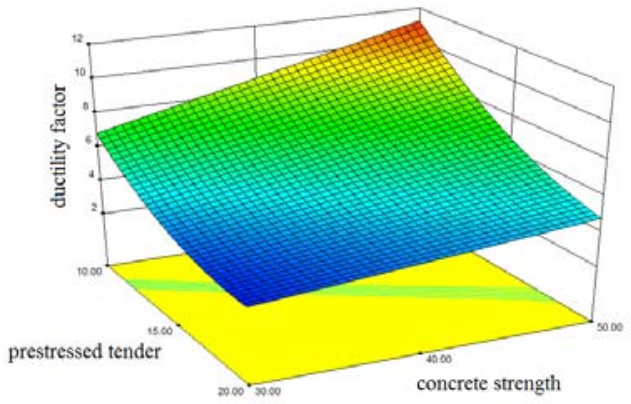

Fig. 8. Relationship between concrete strength, prestressed tendon and ductility factor

The results show that the influence of the prestressed tendon quantity to ductility of prestressed concrete pier is significant and the influence of the longitudinal reinforcement ratio to ductility of prestressed concrete pier is insignificant. With the increasing of the prestressed tendon quantity, the curvature ductility curved reduces. With the increasing of shear 
reinforcement ratio and compressive strength of concrete, the curvature ductility linear increases.

\section{CONCLUSION}

Based on response surface methodology, the ductility of prestressed concrete pier is studied. According to Box-Behnken design, the ductility regression equation is deduced with statistical analysis. The influence of the longitudinal reinforcement ratio, the shear reinforcement ratio, the prestressed tendon quantity and concrete strength grade to curvature ductility is discussed. The results show that:

- The prestressed tendon quantity to ductility of prestressed concrete pier is significant. With the increasing of the prestressed tendon quantity, the curvature ductility curved reduces.

- With the increasing of shear reinforcement ratio and compressive strength of concrete, the curvature ductility linear increases.

- The influence of the longitudinal reinforcement ratio to ductility of prestressed concrete pier is insignificant.

\section{REFERENCES}

[1] P. M. Davis, T. M. Janes, M. O. Eberhard, J. F. Stanton, Unbonded PreTensioned Columns for Bridges in Seismic Regions, Pacific Earthquake Engineering Research Center Headquartered at the University of California, Berkeley, 2012

[2] J. T. Hewes, M. J. N. Priestley, Seismic Design and Performance of Precast Concrete Segmental Bridge Columns, San Diego, La Jolla, California.: University of California 2002

[3] H. I. Jeong, J. Sakai, S. A. Mahin, Shaking Table Tests and Numerical Investigation of Self-Centering Reinforced Concrete Bridge Columns, Berkeley, California.: University of California, Berkeley, 2008

[4] R. Yamashita, D. Sanders, Shake Table Testing and an Analytical Study of Unbonded Prestressed Hollow Concrete Columns Constructed with Precast Segments. Report No.:CCEER 05-09, University of Nevada, 2005

[5] C. A. Cruz-Noguez, M. S. Saiidi, Experimental and Analytical Seismic Studies of a Four-Span Bridge System with Innovative materials. Report No.:CCEER-10-04, University of Nevada, 2010.

[6] S. Motaref, M. Saiidi, D. Sanders, Seismic Response of Precast Bridge Columns with Energy Dissipating Joints, Report No.:CCEER 11-01, University of Nevada, 2011

[7] A. N. Kallias, M. I. Rafiq, "Performance assessment of corroding RC beams using response surface methodology", Engineering Structures, Vol.49, pp. 671-685, 2013

[8] J. Bi, H. Fang, Q. Wang, X. Ren, "Modeling and optimization of foamfilled thin-walled columns for crashworthiness designs", Finite Elements in Analysis and Design, Vol. 46, No. 9, pp. 798-709, 2010
[9] J. Seo, D. G. Linzell, "Horizontally curved steel bridge seismic vulnerability assessment", Engineering Structures, Vol.34, pp. 21-32, 2012

[10] M. N. Hosseinpour, G. D. Najafpour, H. Younesi, M. Khorrami, Z. Vaseghi, "Lipase Production in Solid State Fermentation Using Aspergillus Niger: Response Surface Methodology”, IJE Transactions B: Applications, Vol. 25, No. 3,pp.1 51-159, 2012

[11] N. Aslan, Y. Cebeci, "Application of Box-Behnken design and response surface methodology for modeling of some Turkish coals", Fuel, Vol. 86, pp. 90-97, 2007

[12] M. A. Kalam, A. A. Khan, S. Khan, A. Almalik, A. Alshamsan, "Optimizing indomethacin-loaded chitosan nanoparticle size, encapsulation, and release using Box-Behnken experimental design", International Journal of Biological Macromolecules, Vol. 87, pp.329340, 2016

[13] Y. Ding, J. Zheng, X. Xia, T. Ren, J. Kan, "Box-Behnken design for the optimization of nanoscale retrograded starch formation by high-power ultrasonication", LWT-Food Science and Technology, Vol. 67, pp. 206213, 2016

[14] M. Balasubramanian, "Application of Box-Behnken design for fabrication of titanium alloy and 304 stainless steel joints with silver interlayer by diffusion bonding", Materials \& Design, Vol. 77, pp. 161169,2015

[15] G. E. P. Box, K. B. Wilson, "On the Experimental Attainment of Optimum Conditions (with discussion)", Journal of the Royal Statistical Society Series B13, Vol. 1, pp.1-45, 1951

[16] W. A. A. Alqaraghuli, A. F. M. Alkarkhi, H. C. Low, "Fitting Secondorder Models to Mixed Two-level and Four-level Factorial Designs:Is There an Easier Procedure?", IJE Transactions B: Applications, Vol. 28, No. 11, pp.1644-1650, 2015

[17] M. A. Bezerra, R. E. Santelli, E. P. Oliveira, L. S. Villar, "Response surface methodology (RSM) as a tool for optimization in analytical chemistry", Talanta, Vol. 76, pp.965-977,2008

[18] S. L. C. Ferreira, R. E. Bruns, H. S. Ferreira, G. D. Matos, J. M. David, "Box-Behnken design: An alternative for the optimization of analytical methods", Analytica Chimica Acta, Vol. 597, No. 2, pp. 179-186, 2007

[19] J. Lee, G. L. Fenves, "Plastic-damage model for cyclic loading of concrete structures", Journal of Engineering Mechanics, Vol. 124, pp. 892-900, 1998

[20] H. Wang, S. Liu, Z. Zhang, "Seismic Performance and Effects of Different Joint Shapes for Unbonded Precast Segmental Bridge Columns", Journal of Mechanics, Vol. 32, No. 4, pp. 427-433, 2016

[21] O. Saghaeian, F. Nateghi, O. Rezaifar, "Comparison of using Different Modeling Techniques on Prediction of the Nonlinear Behavior of R/C Shear Walls", IJE Transactions B: Applications, Vol. 27, No. 2, pp. 269282, 2014

[22] Z. Yang, Y. Zhang, M. Chen, G. Chen, "Numerical simulation of ultrastrength concrete-filled steel columns", Engineering Review, Vol. 33, No. 3, pp. 211-217, 2013

[23] B. A. Suprenant, Curvature ductility of reinforced and prestressed concrete columns, Bozeman: Montana State University, 1984

[24] A. Namdar, X. Feng, "Economical considerations in the development of construction materials-a review", Engineering Review, Vol. 35, No. 3,pp. 291-297, 2015 